Supporting Information

\title{
Nanomechanical Approach for Flexibility of Organic- Inorganic Hybrid Perovskite Solar Cells
}

Seung-min Ahn ${ }^{\dagger}$ Eui Dae Jung ${ }^{\dagger}$, Si-Hoon Kim, Hangeul Kim, Sukbin Lee, Myoung Hoon Song*, Ju-Young Kim*

School of Materials Science and Engineering, UNIST (Ulsan National Institute of Science and Technology), UNIST-gil 50, Ulsan 44919, Republic of Korea 


\section{I . Supplementary Figures}


Figure S1. SEM images for fracture surfaces of (a) as-heat treated and (b) $80^{\circ} \mathrm{C}$ solventannealed $\mathrm{MAPb}\left(\mathrm{I}_{0.87} \mathrm{Br}_{0.13}\right)_{3}$ samples. Supplementary lines show intergranular fracutre for the as-heat treated samples and transgranular fracutre for $80^{\circ} \mathrm{C}$ solvent-annealed samples. 

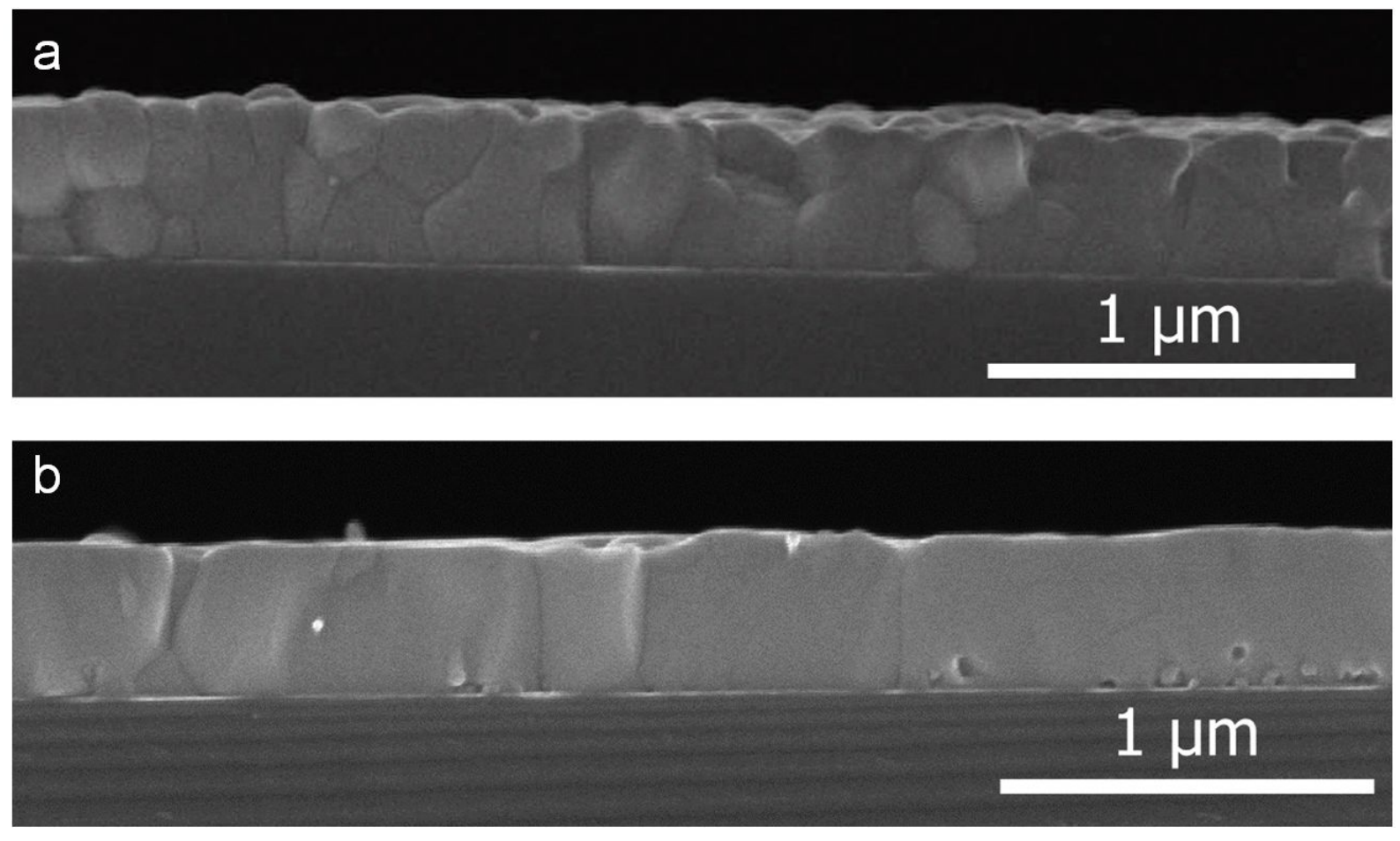

Figure S2. Cross-section SEM images of two different annealed $\mathrm{MAPb}\left(\mathrm{I}_{0.87} \mathrm{Br}_{0.13}\right)_{3}$ samples,

(a) sharp cusps in as-heat treat $\operatorname{MAPb}\left(\mathrm{I}_{0.87} \mathrm{Br}_{0.13}\right)_{3}$, (b) blunt cusps in solvent annealed $\operatorname{MAPb}\left(\mathrm{I}_{0.87} \mathrm{Br}_{0.13}\right)_{3}$. 




Figure S3. Elastic deformation limit of $\mathrm{MAPbI}_{3}$ and three $\mathrm{MAPb}\left(\mathrm{I}_{0.87} \mathrm{Br}_{0.13}\right)_{3}$ samples with different grain size. 

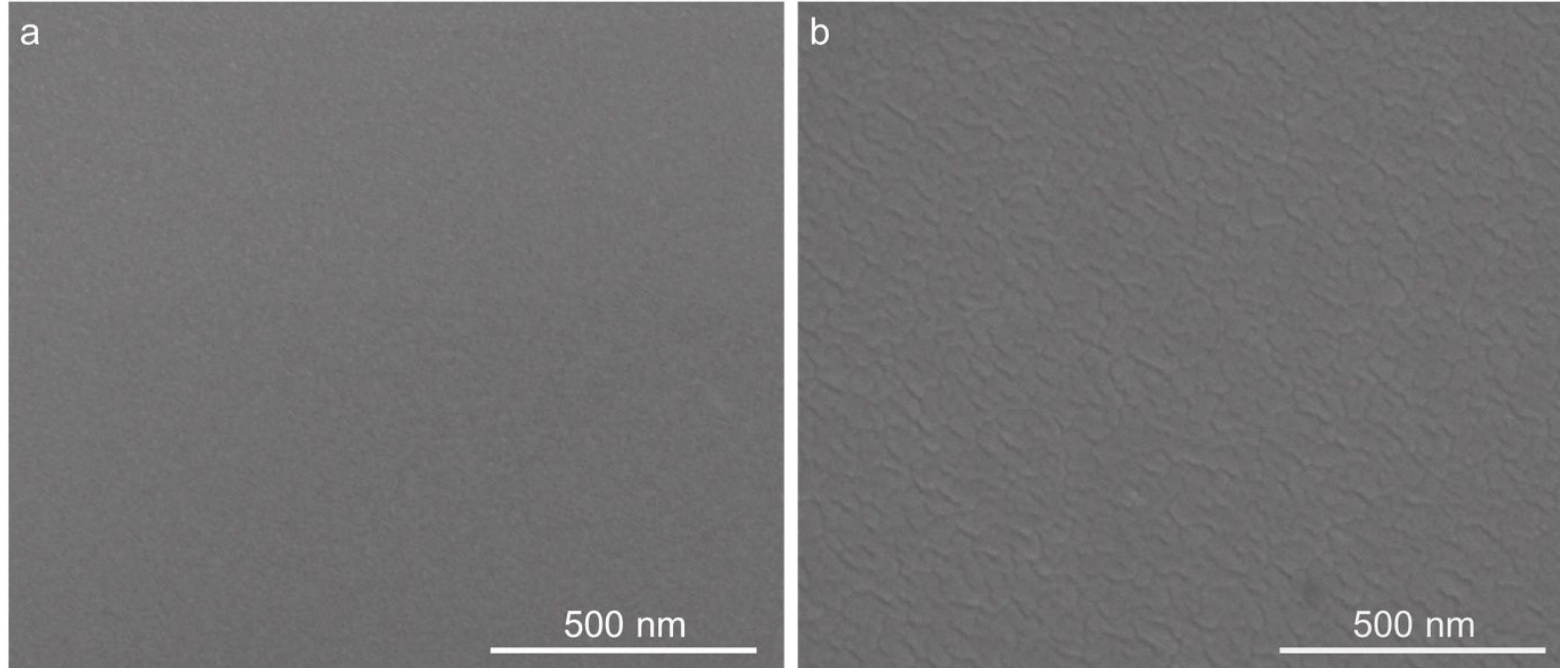

Figure S4. SEM images of Au electrodes with or without PEI, (a) PEI/Au electrode, (b) Au electrode. 

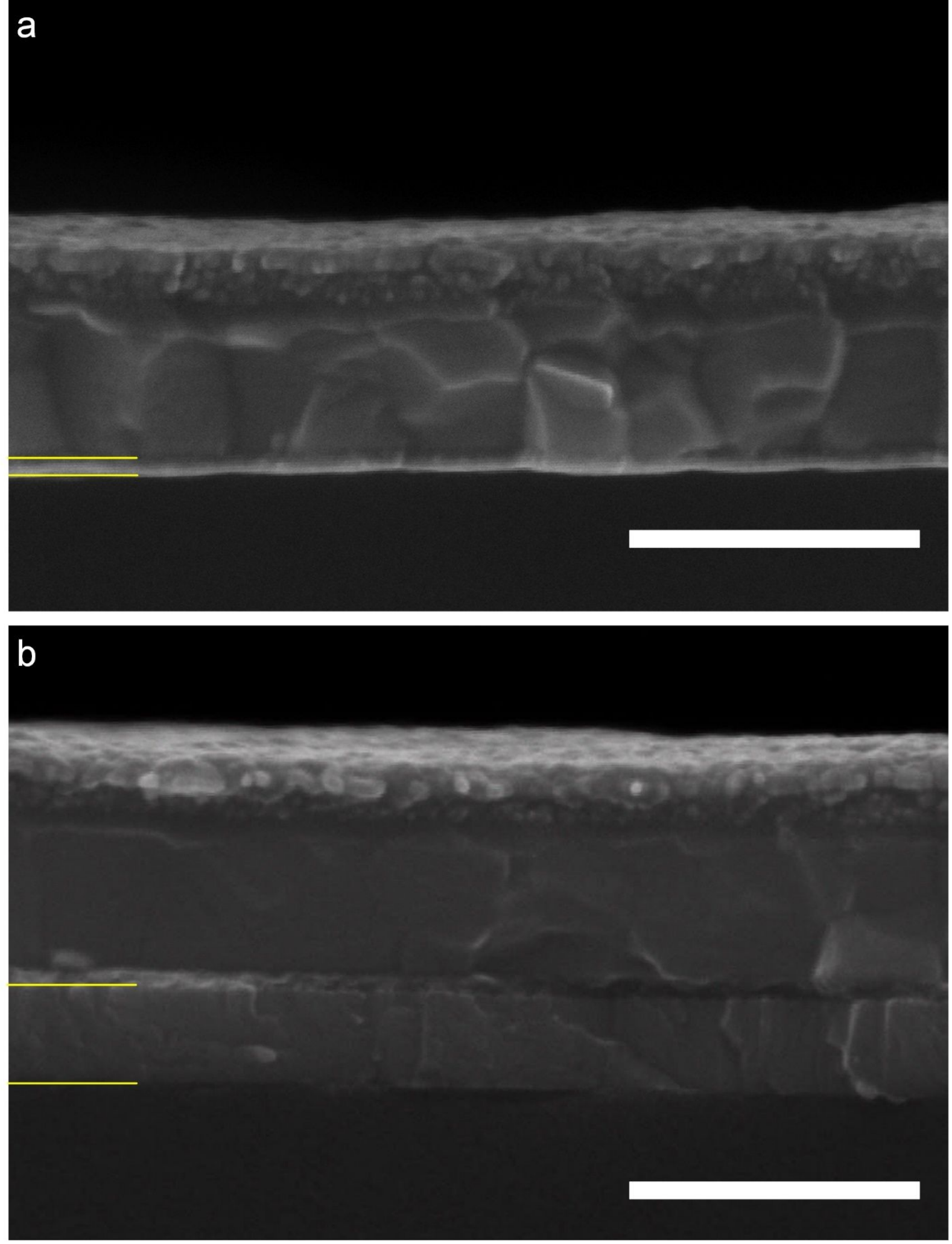

Figure S5. Cross-section SEM images of flexible PSCs with different electrode, (a) PEI/Au electrode, (b) ITO electrode. (Scale bar: $500 \mathrm{~nm}$ ) 


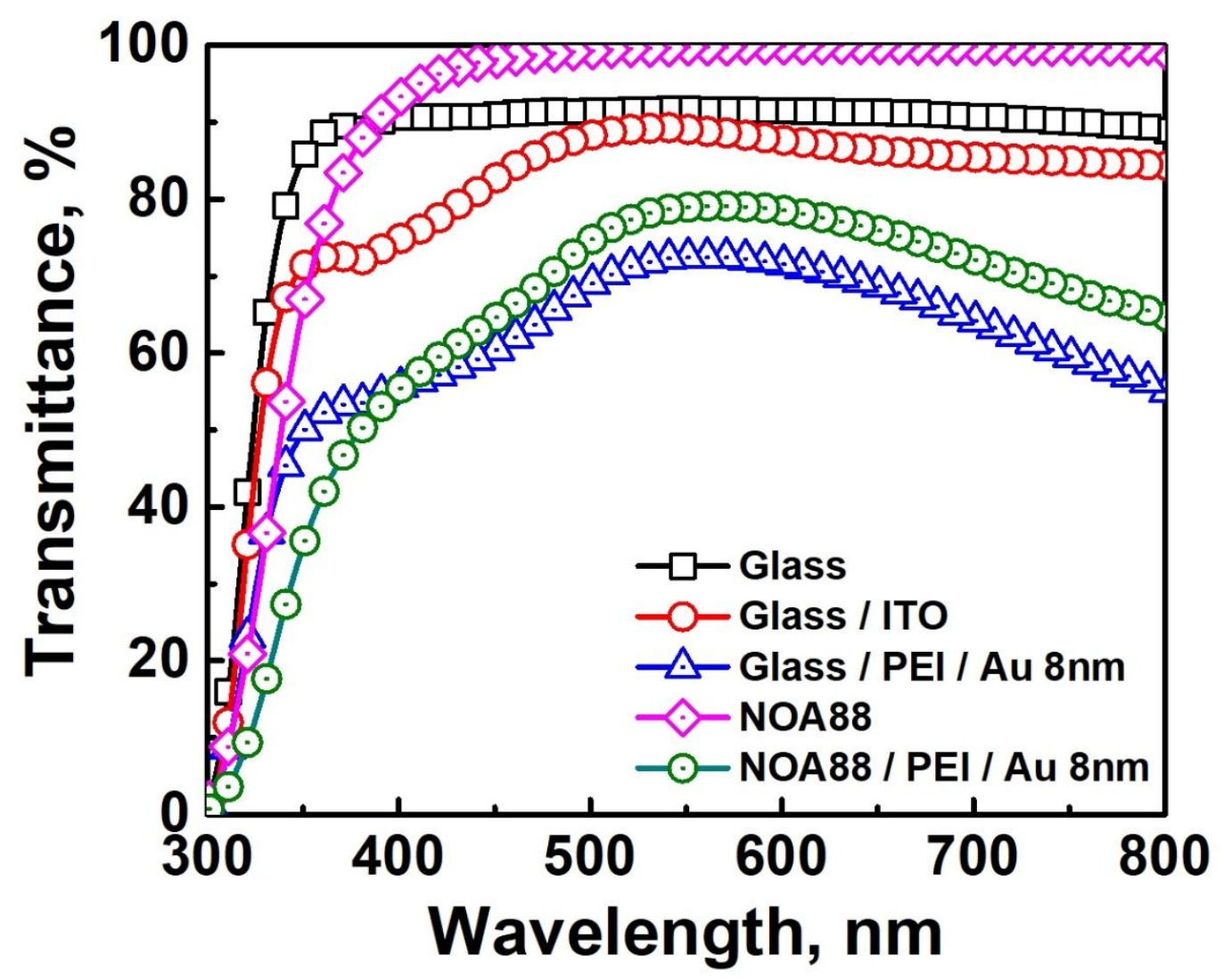

Figure S6. Transmittance of various substrates and electrodes. 
a

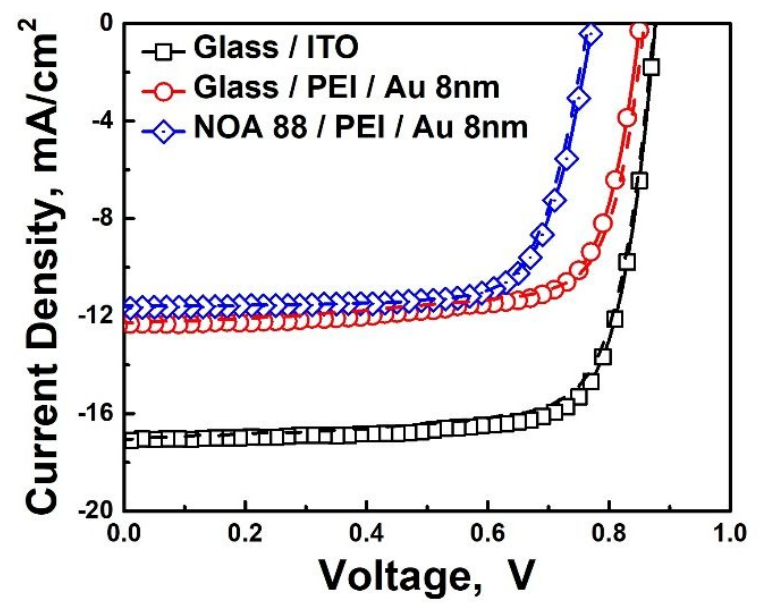

b



Figure S7. (a) Typical J-V curves of PSCs with different substrates and electrodes. (b) External quantum efficiency of PSCs with different substrates and electrodes. 


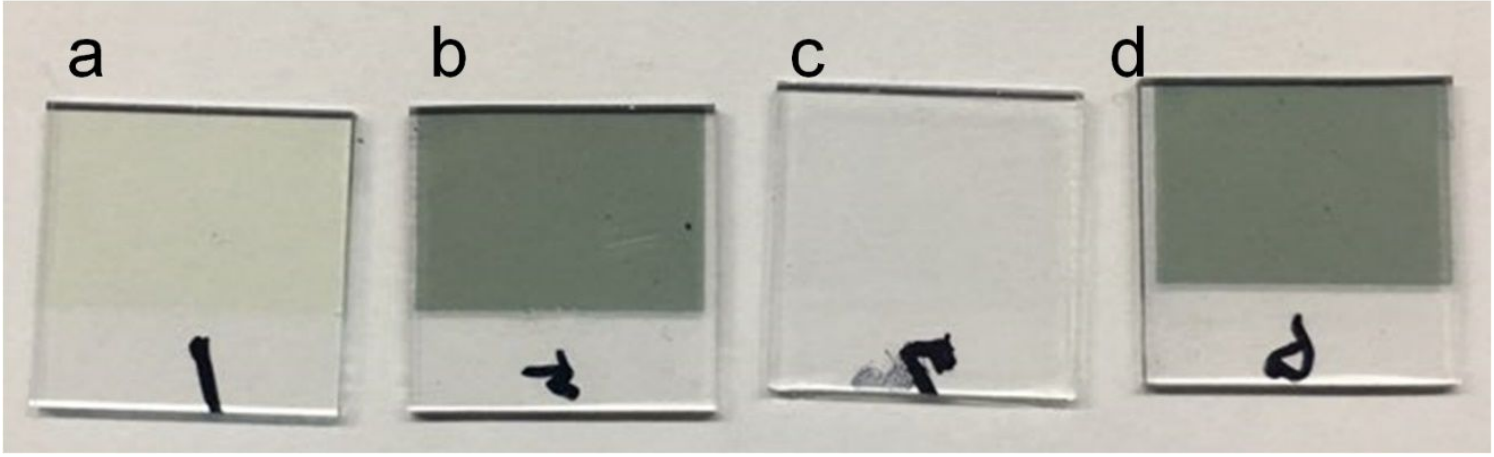

Figure S8. Images of various transparent electrodes and substrate, (a) Glass/ITO, (b) Glass/PEI/Au, (c) Glass/NOA 88, (d) NOA 88/PEI/Au 
Figure S9. Optical microscopy image of crack-initiated ITO electrode with bending radius of $8 \mathrm{~mm}$. 


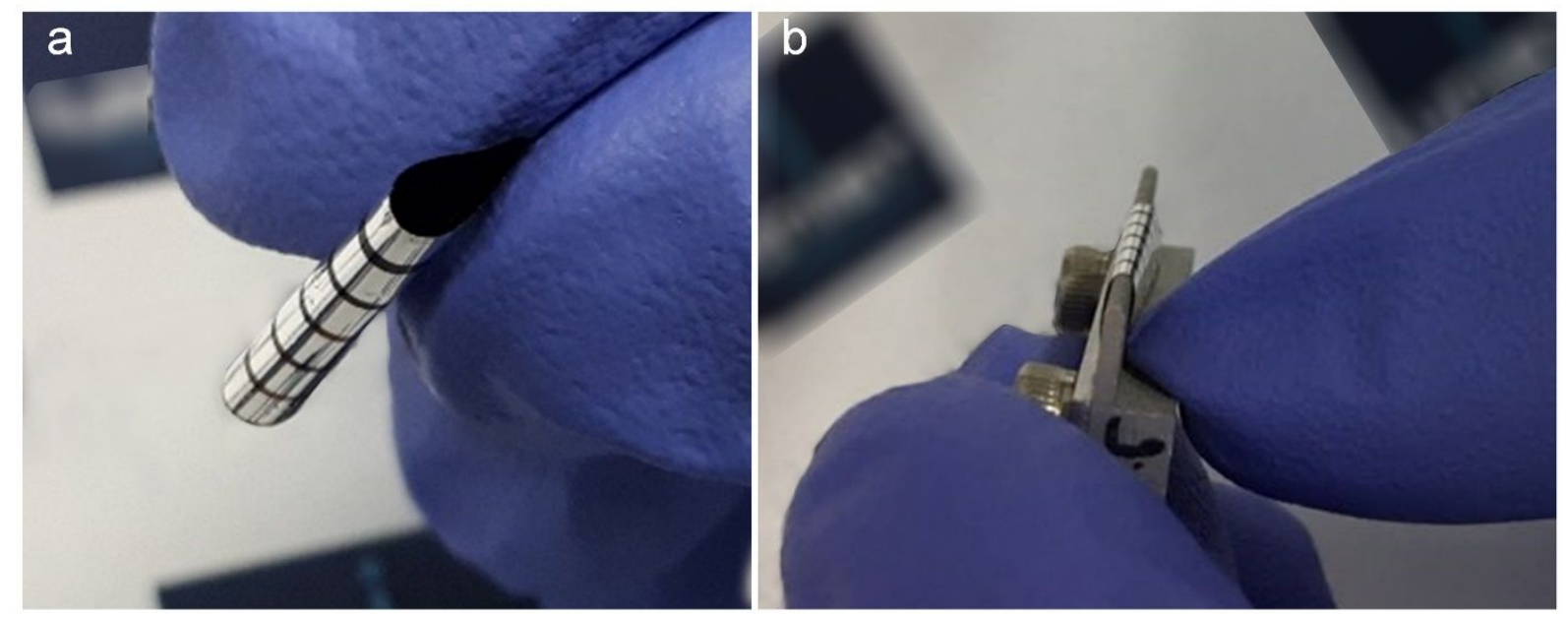

Figure S10. Flexible PSCs using PEI/Au electrodes. (a) Bendability of PSCs. (b) Repeatable bending tests with $0.5 \mathrm{~mm}$ bending radius. 

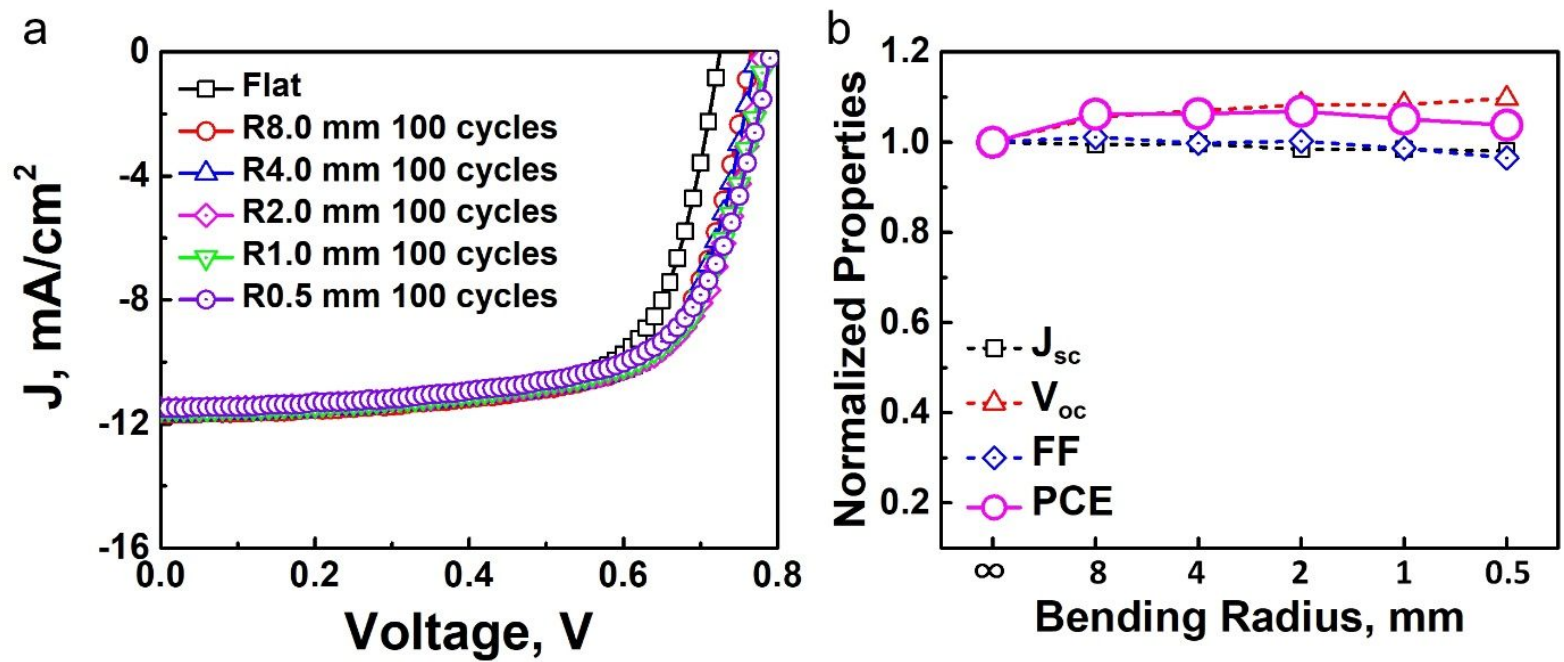

Figure S11. Photovoltaic properties of flexible PSCs with 100 bending cycles, (a) J-V curves of flexible PSCs with different bending radius, (b) Normalized photovoltaic properties of flexible PSCs with different bending radius. 

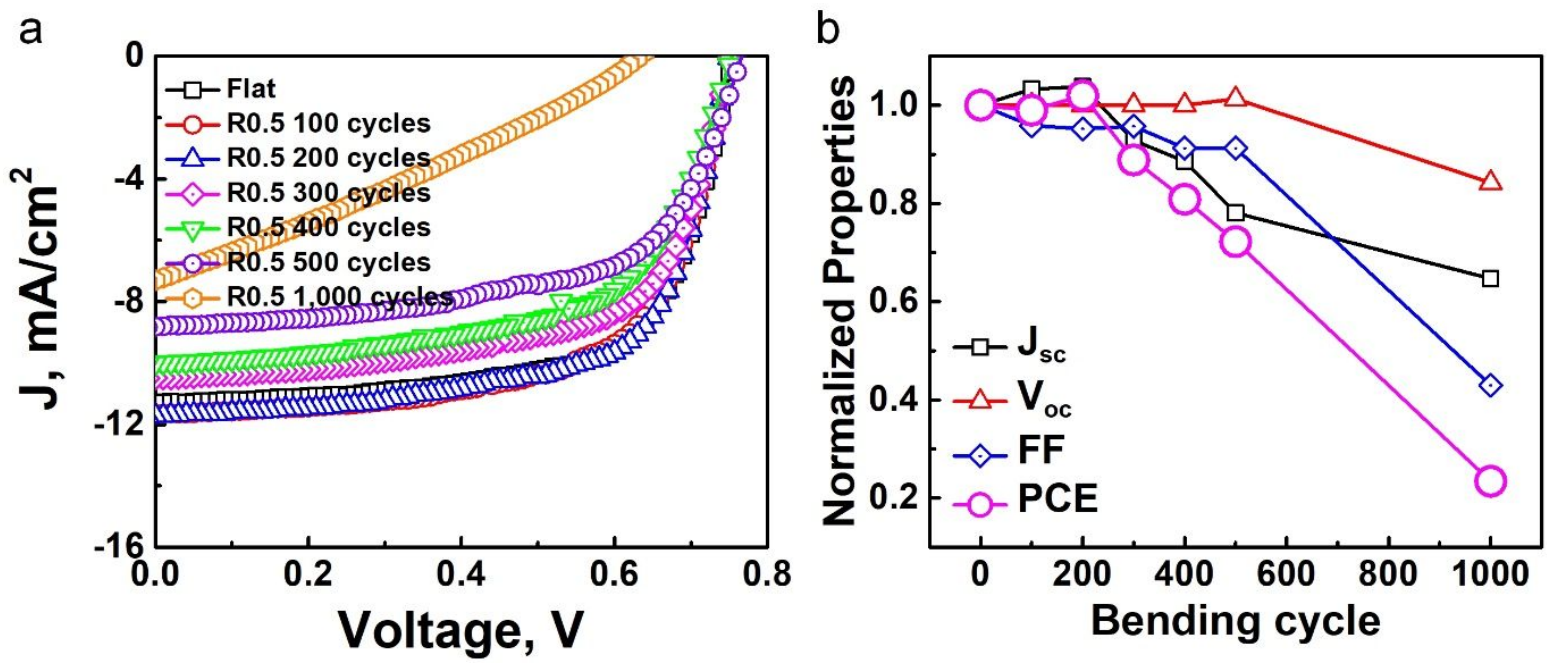

Figure S12. Photovoltaic properties of flexible PSCs with $0.5 \mathrm{~mm}$ bending radius, (a) J-V curves of flexible PSCs with different bending cycles, (b) Normalized photovoltaic properties of flexible PSCs with different bending cycles. 



glass / sacrificial layer

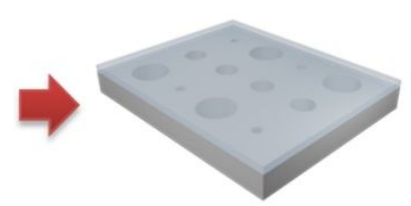

Transfer on hole-patterned substrate

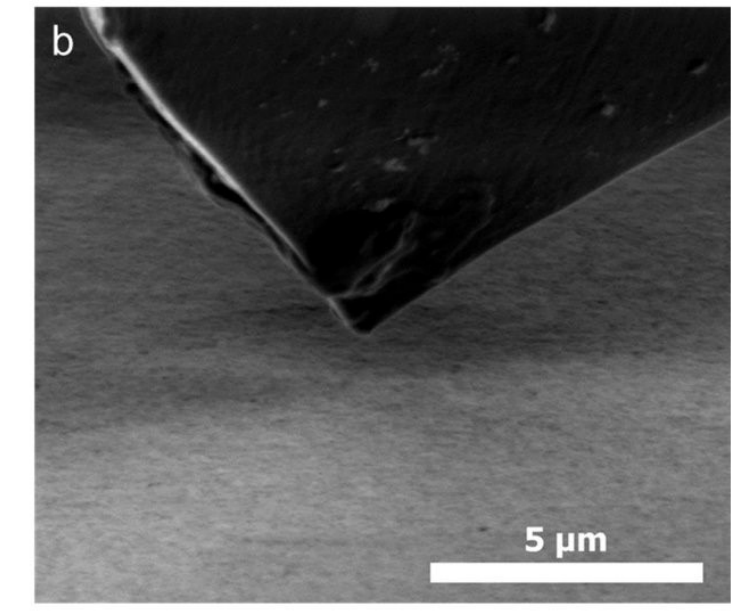

Hole-nanoindentation
Selective etching of sacrificial layer

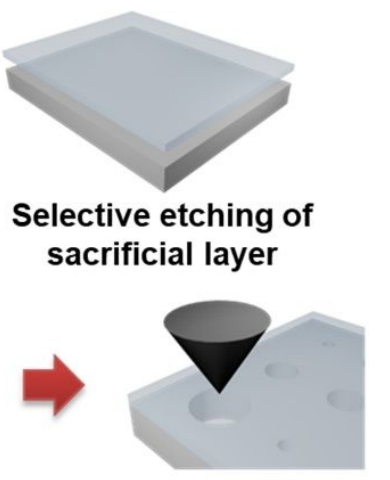

Figure S13. Hole-nanoindentation methods, (a) Schematics of experimental method of holenanoindentation, (b) Typical scanning electron microscopy image of before testing. 
a
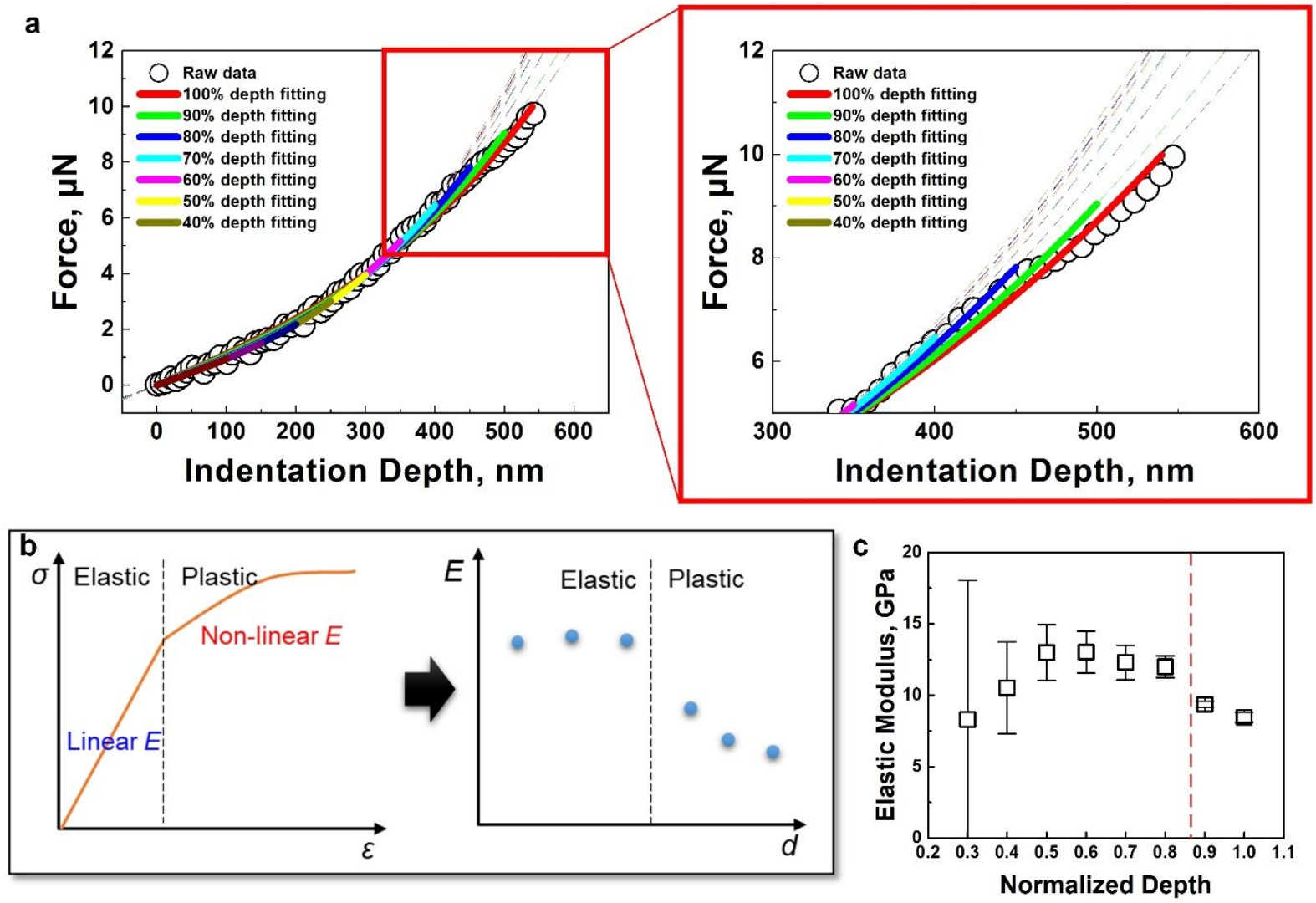

Figure S14. Analysis of elastic deformation range in hole-nanoindentation tests, (a) Typical force-indentation depth curve with fitting curve along with different proportional depth, (b) Schematics of separation methods between elastic and plastic deformation, (c) Elastic modulus with different normalized depth.

* In the hole-nanoindentation tests, it is difficult to distinguish the brittle/ductile behavior of the materials. Therefore, we can be established that the change of linearity of elastic modulus at a certain proportional of indentation depth as a start of plastic deformation. Coincidentally, it was also confirmed that the fitting of equation (2) begins to shift from that point. 


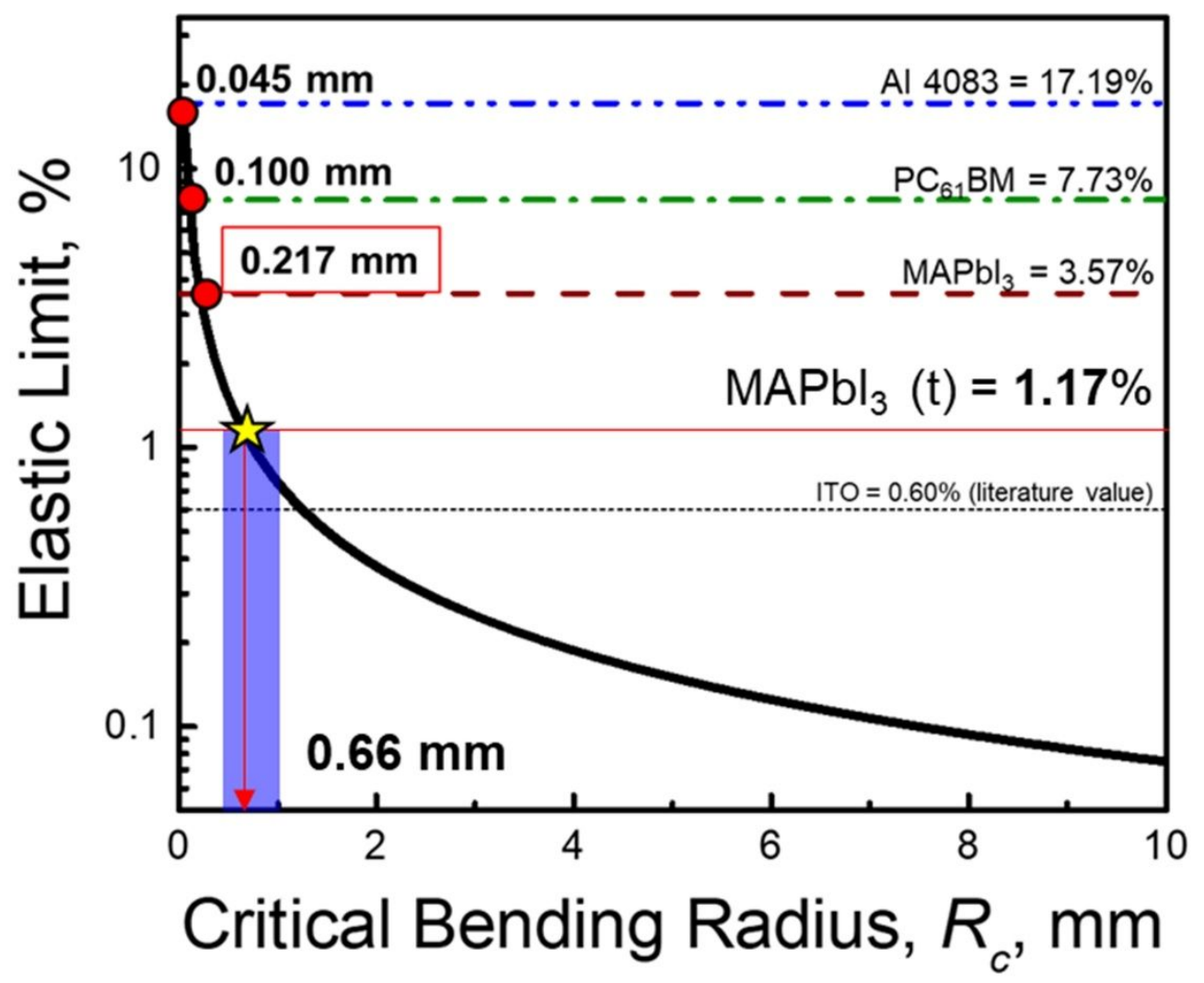

Figure S15. Calculation of critical bending radius based on elastic limit measured by holenanoindentations (overestimated) and uni-axial tensile tests (precise). 




Figure S16. XRD data of $\mathrm{MAPbI}_{3}$ before and after e-beam exposure at $3 \mathrm{kV}$ and $0.2 \mathrm{nA}$ for 2 minutes. 

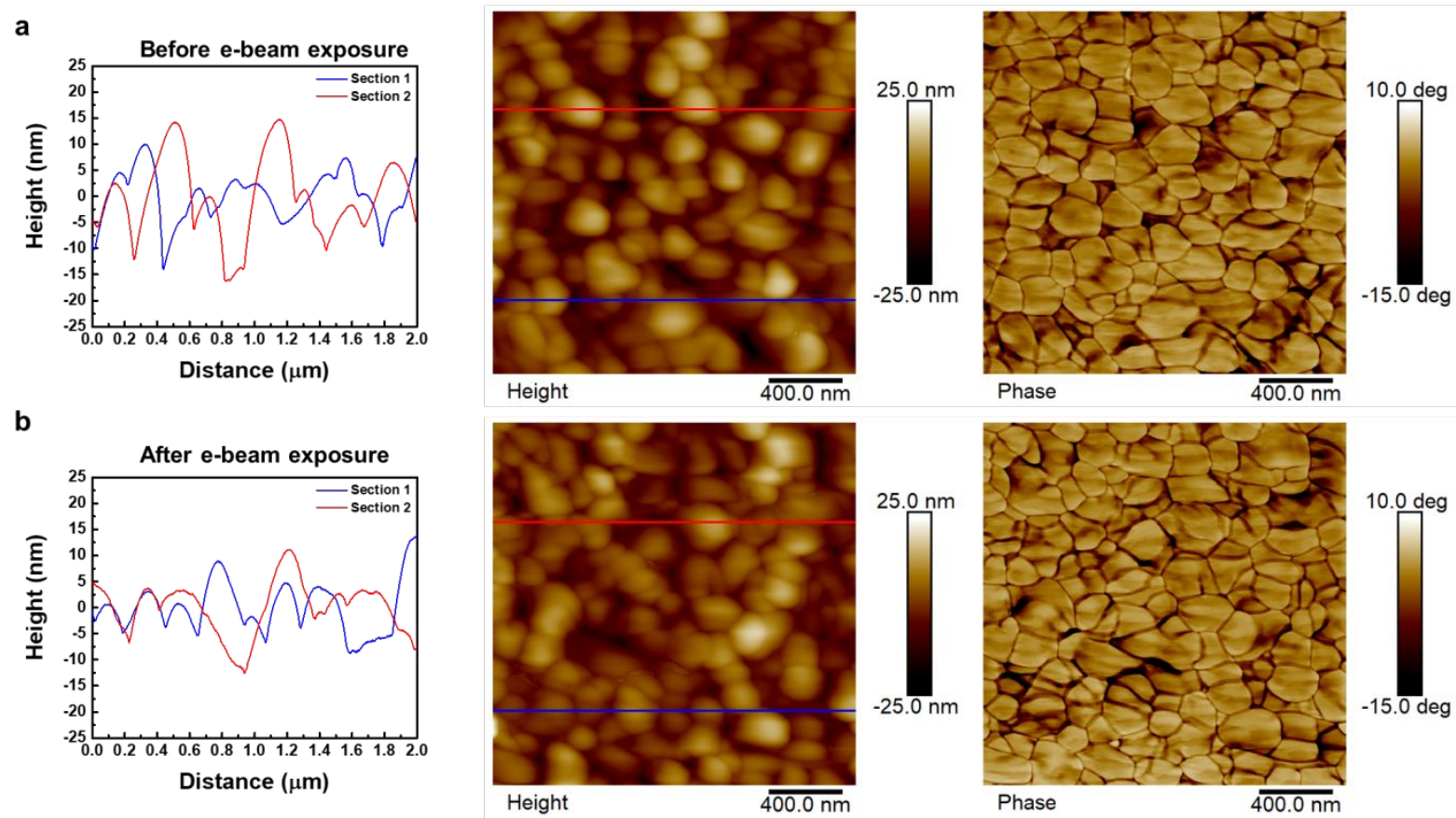

Figure S17. Surface profiles by AFM for

(a) before e-beam exposure, (b) after e-beam exposure at $3 \mathrm{kV}$ and $0.2 \mathrm{nA}$ for 2 minutes.. 


\section{Supplementary Tables}

Table S1. Tensile Properties of $\mathrm{MAPbI}_{3}$ and three $\mathrm{MAPb}\left(\mathrm{I}_{0.87} \mathrm{Br}_{0.13}\right)_{3}$.

\begin{tabular}{lccccc}
\hline Devices configuration & $\begin{array}{c}\text { Grain size } \\
{[\mathrm{nm}]}\end{array}$ & $\mathrm{E}[\mathrm{GPa}]$ & $\sigma \quad[\mathrm{MPa}]$ & $\begin{array}{c}\text { Elastic } \\
\text { limit }[\%]\end{array}$ \\
\hline $\mathrm{MAPbl}_{3}$ & $298.3( \pm 58.6)$ & $5.44( \pm 0.73)$ & $63.23( \pm 7.76)$ & $1.17( \pm 0.13)$ \\
$\mathrm{MAPb}\left(\mathrm{l}_{0.87} \mathrm{Br}_{0.13}\right)_{3}$ as-heat treated & $305.0( \pm 61.9)$ & $4.53( \pm 0.51)$ & $47.4( \pm 4.95)$ & $1.05( \pm 0.10)$ \\
$\mathrm{MAPb}\left(\mathrm{I}_{0.87} \mathrm{Br}_{0.13}\right)_{3} \mathbf{5 0} \mathrm{C}$ solvent-annealed & $628.3( \pm 117.4)$ & $5.40( \pm 0.10)$ & $51.12( \pm 2.02)$ & $0.95( \pm 0.04)$ \\
$\mathrm{MAPb}\left(\mathrm{I}_{0.87} \mathrm{Br}_{0.13}\right)_{3} 80^{\circ} \mathrm{C}$ solvent-annealed & $960.2( \pm 179.3)$ & $6.43( \pm 0.25)$ & $63.41( \pm 3.83)$ & $0.98( \pm 0.05)$ \\
\hline
\end{tabular}


Table S2. Summary of device performance of $\mathrm{MAPbI}_{3}$-based PSCs with different substrates and electrodes.

\begin{tabular}{lcccc}
\hline Devices configuration & $\begin{array}{c}\mathrm{J}_{\mathrm{sc}} \\
{\left[\mathrm{mA} / \mathrm{cm}^{2}\right]}\end{array}$ & $\mathrm{V}_{\text {oc }}[\mathrm{V}]$ & $\mathrm{FF}[\%]$ & $\eta[\%]$ \\
\hline Glass / ITO / Al 4083 / $\mathrm{MAPb}_{3}$ / PCBM / Ag & 16.60 & 0.88 & 76.42 & 11.16 \\
Glass / PEI / Au / Al 4083 / $\mathrm{MAPb}_{3}$ / PCBM / Ag & 12.34 & 0.86 & 73.12 & 7.76 \\
NOA 88 / PEI / Au / Al 4083 / $\mathrm{MAPb}_{3}$ / PCBM / Ag & 11.66 & 0.78 & 73.87 & 6.72 \\
\hline
\end{tabular}

